\title{
Puberty and Ovarian Function in Girls with Type 1 Diabetes Mellitus
}

\author{
Ethel Codner Fernando Cassorla \\ Institute of Maternal and Child Research, School of Medicine, University of Chile, Santiago, Chile
}

\section{Key Words}

Puberty $\cdot$ Thelarche $\cdot$ Menarche $\cdot$ Ovary ·

Hyperandrogenism · Hirsutism • Insulin • Ovary •

Type 1 diabetes mellitus · Growth · Weight •

Polycystic ovarian syndrome

\begin{abstract}
Insulin is well known for its effects on carbohydrate metabolism, but this hormone also plays an important role in regulating ovarian function. Granulosa, theca and stromal ovarian cells may be affected by insulin deficiency or excess, which may be present in women with type 1 diabetes mellitus (T1D). Recent publications have shown that in spite of intensive insulin therapy, some delay in the age of thelarche, pubarche and menarche is still observed in girls with T1D. In addition, ovarian hyperandrogenism may be observed during late adolescence and an increased prevalence of hirsutism and polycystic ovarian syndrome (PCOS) has been described in adult women with T1D. These endocrine abnormalities may be related to nonphysiologic insulin replacement therapy and to hyperglycemia. This paper reviews the pubertal development and the clinical reproductive abnormalities observed in girls with type 1 diabetes mellitus, and shows that several significant clinical problems, such as pubertal delay, menstrual disturbances and hyperandrogenism which may ultimately lead to the development of PCOS in adulthood, may be observed in some of these patients.
\end{abstract}

Copyright $\odot 2008$ S. Karger AG, Basel

\section{Introduction}

Major advances in the treatment of type 1 diabetes mellitus (T1D) children and adolescents have occurred during the last few years. Severe forms of growth and pubertal delay are now rare, but some degrees of delay in growth and pubertal development may still be observed $[1,2]$. During the last decade, the proportion of children with T1D receiving multiple daily insulin injections, which has led to higher insulin daily doses, has increased dramatically [3]. Although the benefits of intensive treatment have been conclusively demonstrated, the hyperinsulinemia associated with this type of treatment maylead to increased body weight and more frequent episodes of hypoglycemia. It is conceivable that intensive insulin treatment may have potential deleterious effects on other organ systems such as the pituitary-gonadal axis.

Manifestations of T1D on the reproductive system, particularly in women, have suffered dramatic changes during the last few years. Several decades ago, women with T1D frequently exhibited hypogonadism associated with poor metabolic control [4]. Subsequently, as medical treatment of T1D improved, abnormalities of the reproductive system became less frequent, but ovarian manifestations of excessive insulin therapy became more com-

Abbreviations: $\mathrm{BMI}=$ Body Mass Index. $\mathrm{C}=$ Control. $\mathrm{PCOS}=$ Polycystic ovary syndrome. $\mathrm{T}=$ Tanner stage. $\mathrm{T} 1 \mathrm{D}=$ type 1 diabetes mellitus. SHBG $=$ Sex hormone binding globulin.

\section{KARGER}

Fax +41613061234 E-Mail karger@karger.ch www.karger.com
(C) 2008 S. Karger AG, Basel

0301-0163/09/0711-0012\$26.00/0

Accessible online at:

www.karger.com/hre
Ethel Codner, MD

Institute of Maternal and Child Research (IDIMI)

School of Medicine, University of Chile

Casilla 226-3, Santiago (Chile)

Tel. +562977 0865, Fax +562424 7240, E-Mail ecodner@med.uchile.cl 
Fig. 1. Pathophysiology of abnormalities of ovarian function in T1D.

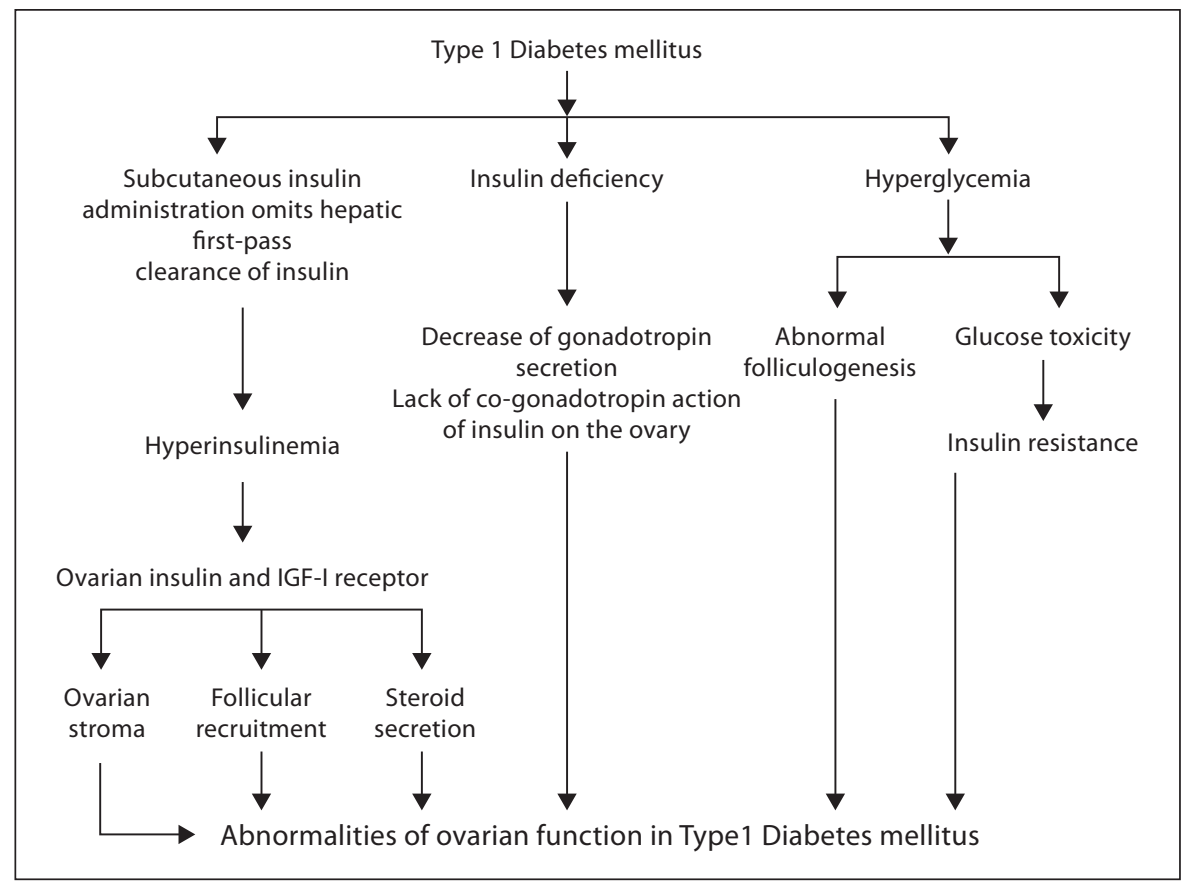

mon $[5,6]$. Thus, a wide range of reproductive abnormalities, associated with either insulin deficiency or excess, may be observed in women with T1D.

The purpose of this review is to provide an update on pubertal development and ovarian function in girls with T1D, based upon our own studies and a review of the literature.

\section{Hypothalamic and Pituitary Function in Women with T1D}

Women with T1D may show amenorrhea and other menstrual disturbances [7]. Studies evaluating T1D women with amenorrhea have found low basal and stimulated gonadotropin levels [8], as observed in hypothalamic amenorrhea [9]. This condition has been explained by the poor metabolic control observed in some of these patients [10]. In addition, increased catecholamine and dopamine levels observed in patients with uncontrolled T1D may also inhibit luteinizing hormone (LH) secretion $[10,11]$.

Studies in mice with streptozotocin-induced diabetes have shown that these animals develop a hypogonadal state with decreased $\mathrm{LH} /$ follicle-stimulating hormone (FSH) and estradiol levels, which are reversed, at least in part, after insulin administration [12]. Adashi et al. [13] showed that insulin has a potent effect on the secretion of
LH and FSH from rat pituitary cells, independent of ambient glucose levels. These findings were subsequently confirmed in knockout mice for the brain insulin receptor who also develop hypogonadotrophic hypogonadism [14].

The mechanism for the decreased gonadotropin levels observed in insulin deficient animals is related to the hypothalamic secretion of GnRH. Knockout mice for the brain insulin receptor respond to exogenous $\mathrm{GnRH}$ by increasing LH levels. These data suggest that under insulin deficiency, higher centers of the central nervous system decrease their GnRH stimuli over the pituitary [14].

\section{Ovarian Function in T1D (fig. 1)}

In contrast to the hypogonadism observed in T1D women with inadequate metabolic control, hyperandrogenism may be observed in some women with T1D, which may be related to the action of exogenous insulin on the ovary. Insulin receptors are present in all the compartments of the ovary, including theca, granulosa and stromal cells $[15,16]$, but insulin may also bind IGF-1 receptors in the ovary. The insulin receptor of the ovary activates both the tyrosine kinase and the inositol pathways, but the main effects of insulin on the ovary are through the latter signaling pathway $[15,16]$. 


\section{Effects of Insulin on Theca Cells}

In vitro studies of theca cells obtained from healthy women have shown that insulin stimulates steroidogenesis $[15,16]$. This response, however, is greatly enhanced when the cells are simultaneously exposed to LH and insulin, leading to the concept that insulin may act as a co-gonadotropin [15]. Insulin stimulates steroid secretion by the theca, increasing the activity of several steroidogenic enzymes (CYP17, p450scc, $3 \beta$ HSD) [16], which may lead to the hyperandrogenism observed in some T1D women [5].

The steroidogenic ovarian response to insulin may vary from one woman to another. In women with polycystic ovarian syndrome (PCOS), a greater ovarian sensitivity to insulin has been described, and some of these patients may exhibit ovarian hyperandrogenism even with normal insulin levels [17]. This susceptibility to hyperandrogenism has been explained by an altered ovarian steroidogenic response to insulin [17]. These data suggest that some women with T1D may be more predisposed to respond abnormally to exogenous insulin [17].

\section{Effects of Insulin on Granulosa Cells}

Insulin receptors are also expressed in granulosa cells, where they play a role in potentiating FSH-stimulated steroid secretion, as shown by increased estrogen secretion by granulosa cells exposed simultaneously to insulin and FSH [18]. In addition, the gonadotropic effect of insulin on folliculogenesis enhances the recruitment and growth of pre-ovulatory follicles [16], decreases the apoptosis and atresia of ovarian follicles [19], and stimulates the passage from primordial to primary follicles [20].

In adult patients with T1D, we have observed an increased ovarian volume and follicle number, which may be explained by the effects of insulin on folliculogenesis [5]. In addition, we recently studied anti-Müllerian hormone serum levels in T1D women with PCOS. This hormone, which represents a marker for the number of small preantral follicles, was not elevated in these women. Therefore, it is more likely that insulin may act as a cogonadotropin enhancing the maturation of large follicles [21], which is quite different from what is observed in other forms of PCOS.

In addition, several studies have investigated the effects of hyperglycemia on ovarian tissue from rats with diabetes induced by streptozotocin. These animals have smaller ovarian preovulatory follicles, delayed oocyte maturation with increased apoptosis and abnormal communication between somatic cells and gametes [22] Colton et al. have also shown that hyperglycemia per se may also affect folliculogenesis in diabetic rats [23].

\section{Exogenous Insulin Therapy}

Under physiologic conditions the pancreas secretes insulin into the portal circulation, and the liver is the organ exposed to the highest insulin concentrations. Thus, the liver has a central role in the regulation of carbohydrate metabolism, inhibiting neoglucogenesis and ketogenesis during the fasting state. This first pass through the liver eliminates $50-70 \%$ of the insulin secreted by the pancreas [24]. In patients with T1D, insulin is administered to the subcutaneous tissue, omitting this hepatic first-pass step and leading to higher systemic insulin levels, which may be detrimental to other organs such as the ovary.

\section{Insulin Resistance}

Insulin resistance, which is classically associated with type 2 diabetes, is also present in T1D due to glucose toxicity, a phenomenon where hyperglycemia leads to peripheral insulin resistance. It should be noted that T1D girls exhibit greater insulin resistance than boys during puberty [25], which may lead to ovarian hyperandrogenism [6]. Poretsky et al. [26] showed that the coexistence of hyperinsulinemia and insulin resistance, as observed in T1D girls, leads more frequently to polycystic ovaries than when either phenomenon is present alone.

In summary, several factors may be involved in altering the ovarian function in girls with T1D. Insulin deficiency may lead to lower gonadotropin levels due to decreased $\mathrm{GnRH}$ secretion. In addition, hyperglycemia may affect the ovary both directly and through the induction of insulin resistance caused by glucose toxicity. Finally, higher insulin serum levels may lead to overstimulation of the insulin and IGF-1 receptors in the ovary, increasing steroid secretion and fostering the development of PCOS.

\section{Pubertal Development and Ovarian Function in Girls with T1D}

\section{Onset of Puberty}

Severe pubertal delay caused by poorly controlled T1D is rarely seen now. However, the timing of pubertal development in T1D girls is still the subject of some debate. As shown in table 1, four studies performed in the 1980s and 1990s reported no difference in the age of thelarche in girls with T1D and healthy controls. Several factors known to affect the timing of puberty, however, were not considered in these studies. For example, the number of girls studied was small $[27,28]$, and/or the results were compared to historical controls [27-29] or to controls from other countries [27, 29]. 
Table 1. Age of onset of puberty assessed by the appearance of breast Tanner stage 2 in type 1 diabetes mellitus and control girls

\begin{tabular}{|c|c|c|c|c|c|c|c|}
\hline & \multirow{2}{*}{$\begin{array}{l}\text { T1D } \\
\text { year published }\end{array}$} & \multirow{2}{*}{$\begin{array}{l}\text { Control group } \\
\text { year published }\end{array}$} & \multicolumn{2}{|c|}{ Number of girls studied, study design } & \multicolumn{3}{|c|}{ Age of thelarche, years } \\
\hline & & & T1D & control & T1D & control & $\mathrm{p}$ value \\
\hline Rohrer et al. [1] & Germany, 2007 & Germany, 2005 & 2,636, longitudinal & $\begin{array}{l}8,689, \\
\text { cross-sectional }\end{array}$ & $11.4 \pm 1.2$ & $10.9 \pm 1.3$ & $<0.001$ \\
\hline Codner et al. [2] & Chile, 2004 & Chile, 2004 & $\begin{array}{l}100, \\
\text { cross-sectional }\end{array}$ & $\begin{array}{l}576, \\
\text { cross-sectional }\end{array}$ & $9.1 \pm 0.3$ & $8.9 \pm 0.1$ & NS \\
\hline Ahmed et al. [28] & UK, 1998 & UK, 1969 & 23 , longitudinal & $\begin{array}{l}192, \\
\text { cross-sectional }\end{array}$ & $10.9 \pm 0.9$ & $11.2 \pm 1.2$ & NS \\
\hline Salerno et al. [58] & Italy, 1997 & not reported & 30 , retrospective & not reported & $10.4 \pm 1.2$ & not reported & NS \\
\hline Du Caju et al. [27] & Belgium, 1995 & Switzerland, 1983 & 22, longitudinal & 142 , longitudinal & $11.6 \pm 1.0$ & 10.9 & NS \\
\hline Clarson et al. [29] & Canada, 1985 & UK, 1969 & 61 , longitudinal & $\begin{array}{l}91, \\
\text { cross-sectional }\end{array}$ & $11.2 \pm 1.3$ & $11.2 \pm 1.2$ & NS \\
\hline
\end{tabular}

The control group in the study by Rohrer et al. [1] included girls who were studied in the 1980s and published in 2005.

NS = Not significant.

In view of the limitations in the available literature, we studied a large group of T1D girls and a concomitant control group, carefully matched both by ethnicity and socio-economic status [2]. We evaluated 100 T1D and 576 healthy girls in a cross-sectional study, and observed a similar age of onset of thelarche in both groups, which occurred one and a half years earlier than historical controls. We conclude that both groups were following the secular trend towards an earlier onset of puberty, which is similar to the tendency for an earlier thelarche described in the USA [30].

Recently, Rohrer et al. [1] published a large longitudinal study of 2,578 girls from 200 German centers who were participating in a quality control study for diabetes patients. The T1D subjects were treated with 1-7 daily injections and the control group was derived from a large cross-sectional study evaluating pubertal development in 8,689 healthy girls in the mid-1980s. Rohrer et al. [1] observed that T1D girls develop thelarche 6 months later than control girls, although the reported age is within the normal range for both groups. The fact that the T1D and control groups were not recruited simultaneously does not limit the conclusions of this study, since the trend for an earlier onset of puberty in healthy girls would increase the difference between both groups. The authors performed a logistic regression analysis and reported that a higher BMI and a lower HbAlc, but not the number of insulin daily doses, were associated with an earlier onset of puberty.

In conclusion, most series have shown that the age of onset of puberty in girls with T1D is within the normal
Table 2. Age of pubertal events in T1D patients and control girls in two recent series

\begin{tabular}{|c|c|c|c|c|}
\hline & \multicolumn{2}{|c|}{ German study [1], years } & \multicolumn{2}{|c|}{ Chilean study [2], years } \\
\hline & T1D & $\mathrm{C}$ & T1D & $\mathrm{C}$ \\
\hline \multicolumn{5}{|c|}{ Breast Tanner stage } \\
\hline 2 & $11.4 \pm 1.2$ & $10.9 \pm 1.3^{\mathrm{d}}$ & $9.1 \pm 0.3$ & $8.9 \pm 0.1$ \\
\hline 3 & $12.8 \pm 1.4$ & $12.5 \pm 2.0^{\mathrm{d}}$ & $11.1 \pm 0.3$ & $10.4 \pm 0.1^{\mathrm{a}}$ \\
\hline 4 & $14.1 \pm 1.6$ & $14.1 \pm 1.6$ & $12.2 \pm 0.2$ & $11.7 \pm 0.1^{\mathrm{a}}$ \\
\hline 5 & $14.9 \pm 1.5$ & $15.3 \pm 0.9$ & $13.3 \pm 0.3$ & $12.8 \pm 0.1^{\mathrm{b}}$ \\
\hline \multicolumn{5}{|c|}{ Pubic hair Tanner stage } \\
\hline 2 & $11.5 \pm 1.2$ & $11.4 \pm 1.1^{\mathrm{c}}$ & $10.6 \pm 0.7$ & $10.3 \pm 0.3$ \\
\hline 3 & $12.8 \pm 1.3$ & $12.5 \pm 1.6^{\mathrm{d}}$ & $11.7 \pm 0.3$ & $11.2 \pm 0.1$ \\
\hline 4 & $14.0 \pm 1.5$ & $13.8 \pm 1.6^{\mathrm{d}}$ & $12.7 \pm 0.2$ & $12 \pm 0.1^{\mathrm{a}}$ \\
\hline 5 & $14.8 \pm 1.5$ & $15.1 \pm 1.0$ & $13.9 \pm 0.3$ & $13.1 \pm 0.1^{\mathrm{a}}$ \\
\hline
\end{tabular}

The results of the German study are shown as mean \pm SD. The results of the Chilean study are shown as mean \pm standard error obtained from probit analysis.

${ }^{\mathrm{a}} \mathrm{p}<0.05 ;{ }^{\mathrm{b}} \mathrm{p}=0.05 ;{ }^{\mathrm{c}} \mathrm{p}<0.01 ;{ }^{\mathrm{d}} \mathrm{p}<0.001$.

range, and probably follows the secular trend for advancement observed in the general population. A mild delay may still be observed in some patients with T1D, which may be associated with poor metabolic control.

\section{Menarche and Final Stages of Pubertal Development} (tables 2, 3)

Very few studies have focused on the final stages of breast and pubic hair development in girls with T1D (ta- 
Table 3. Age of menarche in $\mathrm{T} 1 \mathrm{D}$ and control girls

\begin{tabular}{|c|c|c|c|c|c|}
\hline \multirow[t]{2}{*}{ Author } & \multirow[t]{2}{*}{ Country } & \multirow{2}{*}{$\begin{array}{l}\text { Year } \\
\text { pub- } \\
\text { lished }\end{array}$} & \multicolumn{2}{|c|}{ Age of menarche, years } & \multirow[t]{2}{*}{ Factor associated with the age of menarche } \\
\hline & & & T1D & $\mathrm{C}$ & \\
\hline Picardi et al. [32] & Rome, Italy & 2008 & $12.6 \pm 1.5$ & $12.3 \pm 1.4^{*}$ & duration of T1D \\
\hline Lombardo et al. [33] & Messina, Italy & 2008 & $12.8 \pm 1.1$ & $12.0 \pm 1.1^{* * *}$ & duration of T1D and metabolic control \\
\hline Snell-Bergeon et al. [39] & Denver, USA & 2008 & $13.1 \pm 1.8$ & $12.8 \pm 1.5^{*}$ & \\
\hline Rohrer et al. [1] & Germany & 2007 & $13.2 \pm 1.3$ & $12.7 \pm 1.1^{* * *}$ & $\begin{array}{l}\text { duration of T1D and metabolic control; higher insulin } \\
\text { dose associated with earlier menarche }\end{array}$ \\
\hline Elamin et al. [34] & Sudan & 2006 & $15.1 \pm 1.3$ & $13.3 \pm 0.2^{* *}$ & \\
\hline Danielson et al. [31] & Wisconsin, USA & 2005 & $12.8 \pm 1.3$ & $12.5^{*}$ & duration of T1D, metabolic control, ethnicity and BMI \\
\hline Codner et al. [2] & Chile & 2004 & $13.0 \pm 0.2$ & $12.5 \pm 1.1^{*}$ & BMI \\
\hline Donaghue et al. [59] & Australia & 2003 & $\begin{array}{l}13.0^{\mathrm{a}} \\
12.8^{\mathrm{b}}\end{array}$ & $\begin{array}{l}\text { not reported } \\
\text { not reported }\end{array}$ & \\
\hline Strotmeyer et al. [7] & Pittsburgh, USA & 2003 & $13.5 \pm 1.9$ & $12.6 \pm 1.4^{* * *}$ & prepubertal onset of T1D \\
\hline Salerno et al. [58] & Italy & 1997 & $12.8 \pm 1.4$ & $12.5 \pm 1.0$ & \\
\hline Kjær et al. [35] & Denmark & 1992 & $14.2 \pm 1.5$ & $13.4 \pm 1.4^{* * *}$ & prepubertal onset of T1D \\
\hline Schriok et al. [60] & USA & 1984 & $13.4 \pm 1.2$ & $13.0 \pm 1.2$ & onset of T1D during puberty \\
\hline
\end{tabular}

${ }^{*} \mathrm{p}<0.05 ;{ }^{* *} \mathrm{p}<0.01$; ${ }^{* * *} \mathrm{p}<0.001 .{ }^{\text {a }}$ Girls diagnosed between 1974 and 1990; ${ }^{\mathrm{b}}$ girls diagnosed between 1991 and 1995.

ble 2). In our study, we observed that T1D girls exhibit a delay in the attainment of breast Tanner stages 3 and 4 [2]. The German study documented a delay of 4 months for Tanner stage 3 only $[1,2]$, and pubic hair Tanner stages 3 and 4 were delayed in T1D girls from both studies.

In contrast to the few studies evaluating the final stages of development, several publications have reported the effect of T1D on the age of menarche. Table 3 summarizes the findings from several studies, which indicate some delay in the age of menarche in girls with T1D, ranging from 2 to 3 months in Wisconsin, USA [31], Rome [32], and Germany [1], 6-9 months in Chile [2], Messina, Italy [33], and Pittsburgh, Pa., USA [7], and 2 years in Sudan [34]. In addition, the presence of a delayed menarche has been associated with subsequent irregular menses and other gynecological disturbances in T1D women [31, 35-37].

Recently, two Italian series have shown that in spite of intensive insulin therapy, a delay in the age of menarche is still observed in their country. Picardi et al. [32] studied 162 girls who were intensively treated since diagnosis with an average $\mathrm{HbAlc}$ of $7.2 \%$, and observed a three-month delay in menarche. Lombardo et al [33]. studied a group of 73 girls who were intensively treated and observed a 1year delay in the age of menarche compared to the patients' mothers, and 7 months compared to healthy girls.

The main factors which have been associated with a delay in the age of menarche have been poor metabolic control [1, 31], lower BMI [1, 2, 31], prepubertal onset of diabetes $[7,35,36]$ and a longer duration of T1D $[1,31]$ (table 3). Danielson et al. [31] showed that for each percent point increase in glycated hemoglobin, a delay of 1.3 months is observed in the age of menarche, which was later confirmed in the German study [1]. However, Picardi et al. [32] who studied intensively treated girls with an optimal metabolic control, did not find a similar relationship, suggesting that several other factors may be involved in the delay of menarche in girls with T1D. For example, lower insulin doses may be associated with delayed menarche, possibly due to the effects of insulin on the central nervous system [1].

We should also point out that BMI has been identified as an important factor related to the age of menarche in girls with T1D. A higher BMI is associated with an earlier onset of puberty and age of menarche, similar to that observed in healthy girls [30]. The possible mechanisms underlying the relationship of higher BMI and earlier pubertal onset have been reviewed [38]. Similarly, ethnic origin may also affect the age of menarche, as observed in the general population. In the study of Danielson et al. [31], black girls with T1D had their menarche one year earlier than white girls with T1D.

\section{Menstrual Irregularities}

The final stage in the maturation of the gonadal axis is the attainment of regular ovulatory cycles. Adult T1D 
women have a significantly increased frequency of menstrual disorders, compared to the healthy population, with approximately one fourth developing menstrual irregularities $[5,7,35,39]$. The presence of irregular menstrual cycles has been shown to increase the risk of coronary artery disease in women with T1D [39].

Menstrual irregularities are even more frequently observed in adolescents with T1D [7]. Adcock et al. [40] prospectively studied 24 adolescents and observed that $54 \%$ showed menstrual irregularities, associated with a poorer metabolic control and higher BMI. Menstrual disorders during adolescence rise dramatically in girls with T1D when HbAlc levels increase above $10 \%$.

The presence of menstrual irregularities suggests that anovulatory cycles are frequently present in T1D adolescents. Recently, we followed a group of T1D girls during the first 3 years after menarche, evaluating the presence of ovulation through salivary progesterone [41]. We observed a similar frequency of anovulatory cycles during the first year after menarche in T1D and healthy girls. However, during the second year, control girls experience a higher frequency of ovulatory cycles than T1D girls, suggesting that anovulatory cycles may cause the menstrual abnormalities.

Several reasons may explain the high frequency of menstrual disorders in adolescents with T1D, such as a relative decrease in LH pulsatility [42], a delay in the appearance of the positive estrogen feedback loop on the hypothalamic-pituitary axis, and the development of hyperandrogenism $[43,44]$. However, several other factors such as eating disorders and depression [45], substance abuse [46], insulin omission [45], and/or weight gain, which are frequently observed during adolescence, may be related to inadequate metabolic control.

\section{Hyperandrogenism}

Although hyperandrogenism has been classically associated with T2D, increasing evidence shows that T1D women may also exhibit this abnormality [6]. In 1985, Djursing et al. [8] described that adult women with T1D who did not have amenorrhea, had higher androgen levels, suggesting an ovarian origin of their hyperandrogenism. Subsequently, a prevalence of $40 \%$ of clinical or biochemical hyperandrogenism was shown by EscobarMorreale et al. [47] and by our group in Chile [5]. Both groups reported a prevalence of PCOS, according to the $\mathrm{NIH}$ criteria, of 19 and 12\%, respectively. According to the new Rotterdam Criteria, the prevalence rose to 54\%, and with the criteria of the Androgen Excess Society, the prevalence was $31 \%[5,6,47]$. An association of hyperan- drogenism with intensive insulin treatment, but not total daily insulin dose, and with premenarcheal onset of DM, has been described by both groups [5, 47].

Adult women with T1D and PCOS exhibit a milder form of hyperandrogenism compared to nondiabetic PCOS women. The classic PCOS phenotype, oligomenorrhea and hyperandrogenism, is less frequent in diabetic PCOS compared to nondiabetic PCOS women [21]. There is a high frequency of laboratory hyperandrogenism and ultrasonographic diagnosis of polycystic ovaries in T1D women [5], which may be underdiagnosed if only a clinical evaluation is performed. In addition, hirsutism is milder [21,48], explained in part by the protection conferred by the normal sex-hormone-binding globulin (SHBG) levels observed in T1D women.

The hormonal profile of T1D patients presenting with PCOS is somewhat different from that observed in nondiabetic hyperandrogenic women. In the former, although both serum testosterone and androstenedione levels are increased $[5,21,48]$, serum SHBG, gonadotropin, estradiol, anti-Müllerian hormone and DHEAS concentrations are within the normal range. In addition, a high frequency of polycystic ovaries on ultrasonographic studies is observed in adult women and adolescents with T1D $[5,37]$, but the number of follicles and ovarian volume is intermediate between healthy controls and nondiabetic PCOS women [21].

Adolescent girls with T1D exhibit even milder signs of hyperandrogenism than adults, suggesting that the clinical and laboratory findings evolve during the second decade of life $[5,6]$. T1D adolescents show a higher hirsutism score than healthy girls [43]. We studied pubertal Tanner stages 2-5 in T1D girls and observed that $10 \%$ of these girls, but no controls, exhibited a Ferriman-Gallwey score in the 5-8 range, suggesting a mild increase in the presence of body hair.

Higher total and free testosterone levels have been observed by the end of puberty in T1D girls [44], which have been associated with a higher risk of developing microalbuminuria [49] or retinopathy [50]. An ovarian source of this hyperandrogenism has been documented both in adults and pubertal girls $[43,48]$. We evaluated ovarian function in 56 pubertal T1D and 64 control girls, matched for Tanner stage, BMI and age with the leuprolide test, which helps to determine the source of the hyperandrogenism (fig. 2). We observed higher stimulated testosterone and $17 \mathrm{OH}$-progesterone levels by the end of puberty, which suggest the development of ovarian hyperandrogenism at this stage of puberty. A similar conclusion was observed by Virdis et al. [51]. However, even though 


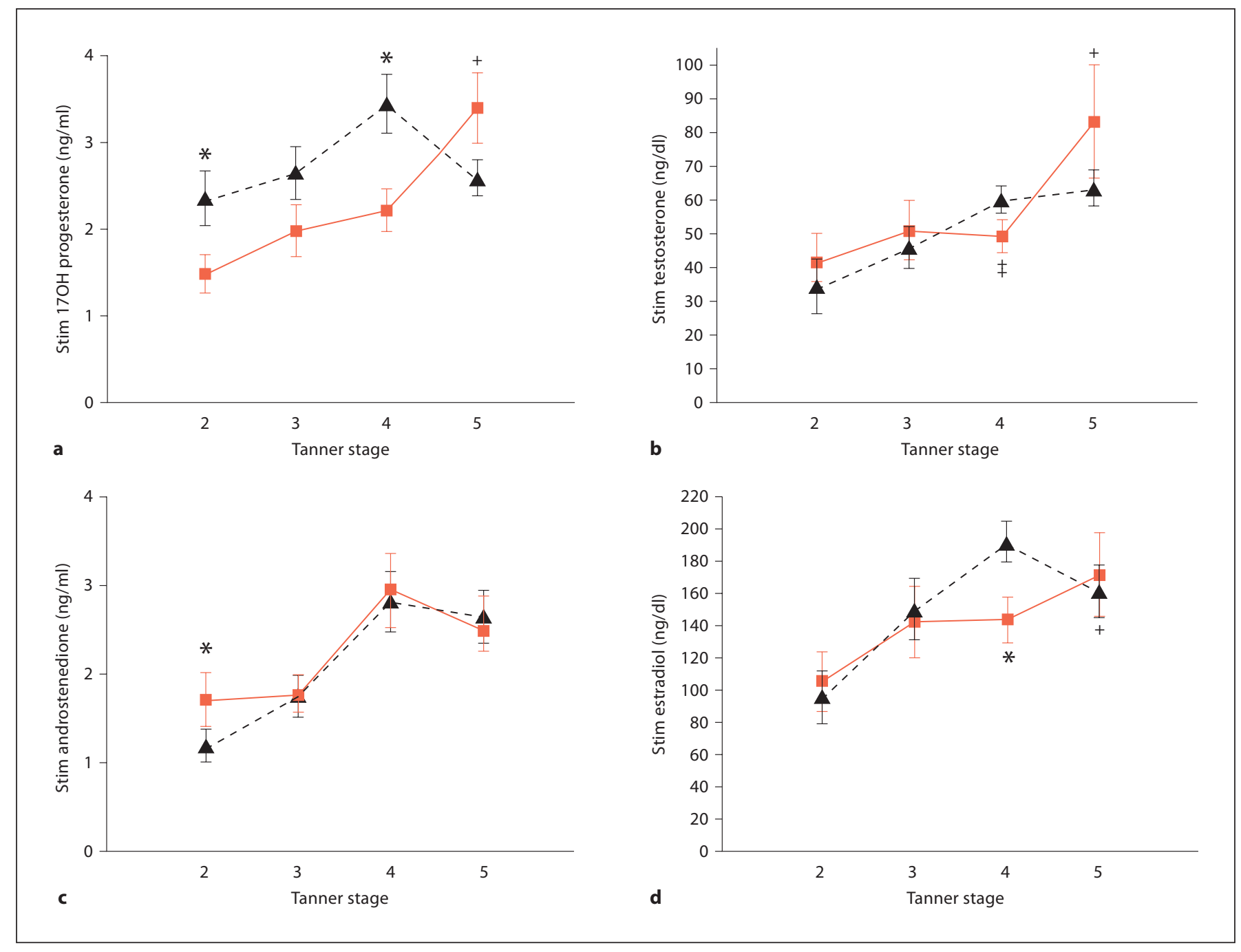

Fig. 2. Steroid levels after stimulation with leuprolide acetate 500 $\mu \mathrm{g}$ s.c. in girls with T1D and control girls according to Tanner stage. Stimulated testosterone, $17 \mathrm{OH}$-progesterone, estradiol, androstenedione were obtained $24 \mathrm{~h}$ after leuprolide acetate injection. Broken line and triangles in black: control girls; continuous line and squares in red: girls with T1D. Data are shown as average \pm SEM. a Stimulated 17OH-progesterone levels. ${ }^{+}$T1D T5 vs. T1D T2-4, p $<0.05$ (ANOVA), * T1D T2 vs. C T2, p $<0.05$ (MannWhitney U test) and T1D T4 vs. C T4, p $<0.05$ (Mann-Whitney U test). b Stimulated testosterone levels. ${ }^{+}$T1DT5 vs. T1DT2-5, p $<$

the ovary is the main source of androgens in women with T1D, higher adrenal androgens may also be present $[48$, 52]. In addition, adolescent T1D girls, similar to adults, also exhibit a high rate of polycystic ovarian morphology [37] and larger ovarian volumes [43], which have been explained by the stimulatory effect of insulin on ovarian tissue.
0.05 (ANOVA). ${ }^{\ddagger}$ CT4 vs.CT2, p $<0.05$ (ANOVA). c Stimulated androstenedione levels. ${ }^{*}$ T1D T2 vs. C T2, p $<0.05$ (Mann-Whitney's U). d Stimulated estradiol levels. ${ }^{+} \mathrm{C}$ girls showed different estradiol levels at all T, p < 0.01 (ANOVA), * T1D T4 vs. C T4, p < 0.05 (Mann-Whitney U test). To convert units to SI: testosterone $(\mathrm{ng} / \mathrm{dl}) \times 0.0347=\mathrm{nmol} / \mathrm{l}$, androstenedione $(\mathrm{ng} / \mathrm{ml}) \times 3.49=$ $\mathrm{nmol} / \mathrm{l}, \mathrm{DHEAS}(\mathrm{ng} / \mathrm{ml}) \times 0.0027=\mathrm{nmol} / \mathrm{l}$, estradiol $(\mathrm{pg} / \mathrm{ml}) \times$ $3.67=\mathrm{pmol} / \mathrm{l}, 17 \mathrm{OH}$-progesterone $(\mathrm{ng} / \mathrm{ml}) \times 3.03=\mathrm{nmol} / \mathrm{l}$. Copied with permission from Codner et al. [43].

\section{Final Remarks and Conclusions}

Adolescence is a critical period and many of the problems faced by patients with diabetes are of a greater magnitude in females than in males. The explanation for this gender difference is not clear, but may be related to psychological factors and to interactions between estrogen 

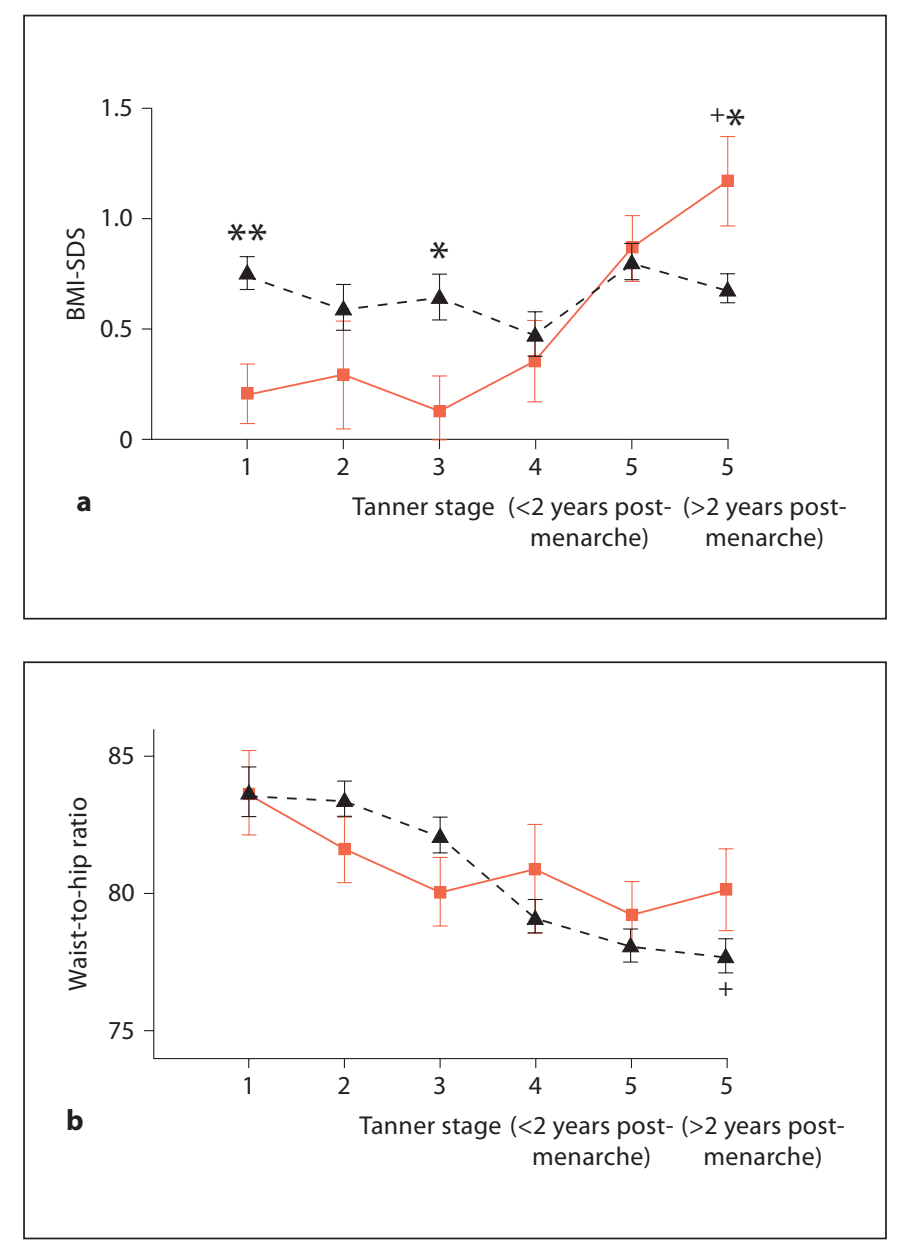

Fig. 3. Body mass index and waist-to-hip ratio during puberty in type 1 diabetes mellitus and control girls. Broken line and triangles in black: control girls; continuous line and squares in red: girls with T1D. Data are shown as average \pm SEM. a Mean BMI (SDS) by Breast Tanner stage. ${ }^{+}$BMI (SDS) increased only in girls with T1DM during puberty (ANOVA $\mathrm{p}<0.01$ Tanner stage 5 vs. Tanner stages 1, 2, 3 and 4). For comparisons between girls with T1D and $C,{ }^{*} \mathrm{p}<0.05$ and ${ }^{* *} \mathrm{p}<0.01$. b Mean waist-to-hip ratio by breast Tanner stage. Waist-to-hip ratio decreased significantly during puberty only in controls $\left({ }^{+}\right.$ANOVA, $p<0.001$ Tanner stages 4 and 5 vs. Tanner stages 1, 2 and 3 ). Reprinted with permission from Codner et al. [2].

levels, insulin therapy, and the growth hormone-IGF axis [53]. In addition, metabolic control deteriorates to a greater extent in girls than in boys during puberty [54], associated with a higher prevalence of microvascular complications [55] and larger weight gain, in particular during late puberty (fig. 3). Gender-specific abnormalities of hormones secreted by adipose tissue, such as leptin and adiponectin, may be involved in the metabolic problems observed in T1D girls during puberty $[56,57]$. Higher leptin

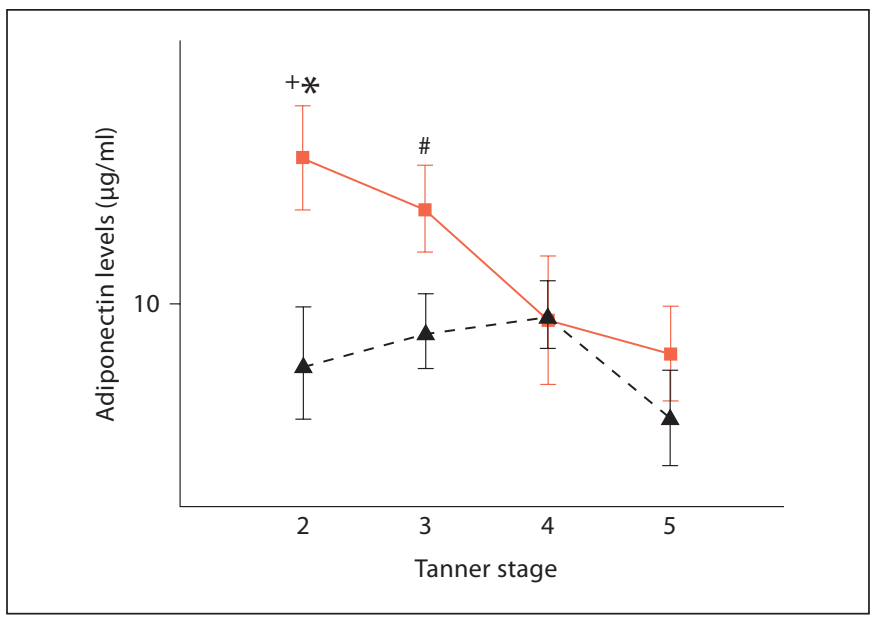

Fig. 4. Adiponectin levels in girls with T1D and control girls according to Tanner stage. Broken line and triangles in black: control girls; continuous line and squares in red: girls with T1D. Data are shown as mean \pm SEM. ${ }^{+}$T1D T5 vs. T1D T2 p $<0.05$ (ANOVA). Adiponectin levels adjusted by BMI were higher in T1D T2 vs. C T2, ${ }^{*} \mathrm{p}=0.013$; T1D T3 vs. C T3, \# $\mathrm{p}=0.051$. Reprinted with permission from Iñiguez et al. [57].

levels, secondary to some degree of resistance to this hormone [56], and decreasing adiponectin levels have been described during puberty in T1D girls (fig. 4).

In conclusion, girls with T1D may show abnormalities in their pubertal development and gonadal function during the second decade of life. During the last few years, the reproductive manifestations observed in girls with T1D have evolved from signs caused by insulin deficiency to those caused by insulin excess. Current insulin treatment modalities are still associated with pubertal delay and menstrual disturbances. In addition, some of these girls may develop hyperandrogenism, which may evolve towards PCOS in adulthood. We hope that future treatment modalities will address some of the current problems observed in pubertal T1D girls, by attempting to deliver insulin in a more physiologic fashion and achieving a better balance between insulin deficiency and insulin excess in these patients.

\section{Acknowledgments}

This work was supported by the Fondo Nacional de Desarrollo Científico y Tecnológico (FONDECYT) grant No. 1050452 to E.C. We are grateful to all the patients who have participated in these studies and to the collaborators in the studies of ovarian function in type 1 diabetes mellitus. 


\section{References}

- 1 Rohrer T, Stierkorb E, Heger S, Karges B, Raile K, Schwab KO, Holl RW: Delayed pubertal onset and development in German children and adolescents with type 1 diabetes: cross-sectional analysis of recent data from the DPV diabetes documentation and quality management system. Eur J Endocrinol 2007;157:647-653.

-2 Codner E, Barrera A, Mook-Kanamori D, Bazaes RA, Unanue N, Gaete X, Avila A, Ugarte F, Torrealba I, Perez V, Panteon E, Cassorla F: Ponderal gain, waist-to-hip ratio, and pubertal development in girls with type-1 diabetes mellitus. Pediatr Diabetes 2004;5:182-189.

-3 de Beaufort CE, Swift PG, Skinner CT, Aanstoot HJ, Aman J, Cameron F, Martul P, Chiarelli F, Daneman D, Danne T, Dorchy H, Hoey H, Kaprio EA, Kaufman F, Kocova M, Mortensen HB, Njolstad PR, Phillip M, Robertson KJ, Schoenle EJ, Urakami T, Vanelli M: Continuing stability of center differences in pediatric diabetes care: do advances in diabetes treatment improve outcome? The Hvidoere Study Group on Childhood Diabetes. Diabetes Care 2007;30:2245-2250.

-4 Bergqvist N: The gonadal function in female diabetics. Acta Endocrinol Suppl (Copenh) 1954;19:1-20.

5 Codner E, Soto N, Lopez P, Trejo L, Avila A, Eyzaguirre FC, Iniguez G, Cassorla F: Diagnostic criteria for polycystic ovary syndrome and ovarian morphology in women with type 1 diabetes mellitus. J Clin Endocrinol Metab 2006;91:2250-2256.

-6 Codner E, Escobar-Morreale HF: Hyperandrogenism and polycystic ovary syndrome in women with type 1 diabetes mellitus. J Clin Endocrinol Metab 2007;92:1209-1216.

-7 Strotmeyer ES, Steenkiste AR, Foley TP Jr, Berga SL, Dorman JS: Menstrual cycle differences between women with type 1 diabetes and women without diabetes. Diabetes Care 2003;26:1016-1021.

${ }_{8}$ Djursing H, Hagen C, Nyboe Andersen A, Svenstrup B, Bennett P, Molsted Pedersen L: Serum sex hormone concentrations in insulin dependent diabetic women with and without amenorrhoea. Clin Endocrinol (Oxf) 1985;23:147-154.

-9 Griffin ML, South SA, Yankov VI, Booth RA Jr, Asplin CM, Veldhuis JD, Evans WS: Insulin-dependent diabetes mellitus and menstrual dysfunction. Ann Med 1994;26:331340.

10 Arrais RF, Dib SA: The hypothalamus-pituitary-ovary axis and type 1 diabetes mellitus: a mini review. Hum Reprod 2006;21:327337.

11 Djursing H, Andersen AN, Hagen C, Petersen K: Gonadotropin secretion before and during acute and chronic dopamine-receptor blockade in insulin-dependent diabetic patients with amenorrhea. Fertil Steril 1985; 44:49-55.
12 Bestetti GE, Junker U, Locatelli V, Rossi GL: Continuous subtherapeutic insulin counteracts hypothalamopituitary-gonadal alterations in diabetic rats. Diabetes 1987;36:13151319.

13 Adashi EY, Hsueh AJ, Yen SS: Insulin enhancement of luteinizing hormone and follicle-stimulating hormone release by cultured pituitary cells. Endocrinology 1981; 108:1441-1449.

14 Bruning JC, Gautam D, Burks DJ, Gillette J, Schubert M, Orban PC, Klein R, Krone W, Muller-Wieland D, Kahn CR: Role of brain insulin receptor in control of body weight and reproduction. Science 2000;289:21222125.

15 Poretsky L, Kalin MF: The gonadotropic function of insulin. Endocr Rev 1987;8:132141.

16 Poretsky L, Cataldo NA, Rosenwaks Z, Giudice LC: The insulin-related ovarian regulatory system in health and disease. Endocr Rev 1999;20:535-582.

17 Baillargeon JP, Nestler JE: Commentary: polycystic ovary syndrome: a syndrome of ovarian hypersensitivity to insulin? J Clin Endocrinol Metab 2006;91:22-24.

18 Willis D, Mason H, Gilling-Smith C, Franks S: Modulation by insulin of follicle-stimulating hormone and luteinizing hormone actions in human granulosa cells of normal and polycystic ovaries. J Clin Endocrinol Metab 1996;81:302-309.

19 Hsueh AJ, Billig H, Tsafriri A: Ovarian follicle atresia: a hormonally controlled apoptotic process. Endocr Rev 1994;15:707724.

20 Kezele PR, Nilsson EE, Skinner MK: Insulin but not insulin-like growth factor-1 promotes the primordial to primary follicle transition. Mol Cell Endocrinol 2002;192: 37-43.

-21 Codner E, Iniguez G, Villarroel C, Lopez P, Soto N, Sir-Petermann T, Cassorla F, Rey RA: Hormonal profile in women with polycystic ovarian syndrome with or without type $1 \mathrm{di}$ abetes mellitus. J Clin Endocrinol Metab 2007;92:4742-4746.

22 Chang AS, Dale AN, Moley KH: Maternal diabetes adversely affects preovulatory oocyte maturation, development, and granulosa cell apoptosis. Endocrinology 2005;146: 2445-2453.

23 Colton SA, Pieper GM, Downs SM: Altered meiotic regulation in oocytes from diabetic mice. Biol Reprod 2002;67:220-231.

24 Polonsky KS, Given BD, Hirsch L, Shapiro ET, Tillil H, Beebe C, Galloway JA, Frank BH, Karrison T, Van Cauter E: Quantitative study of insulin secretion and clearance in normal and obese subjects. J Clin Invest 1988;81:435-441.
25 Szadkowska A, Pietrzak I, Mianowska B, Bodalska-Lipinska J, Keenan HA, ToporowskaKowalska E, Mlynarski W, Bodalski J: Insulin sensitivity in type 1 diabetic children and adolescents. Diabet Med 2008;25:282-288.

26 Poretsky L, Clemons J, Bogovich K: Hyperinsulinemia and human chorionic gonadotropin synergistically promote the growth of ovarian follicular cysts in rats. Metabolism 1992;41:903-910.

27 Du Caju MV, Rooman RP, op de Beeck L: Longitudinal data on growth and final height in diabetic children. Pediatr Res 1995;38: 607-611.

28 Ahmed ML, Connors MH, Drayer NM, Jones JS, Dunger DB: Pubertal growth in IDDM is determined by HbAlc levels, sex, and bone age. Diabetes Care 1998;21:831835.

29 Clarson C, Daneman D, Ehrlich RM: The relationship of metabolic control to growth and pubertal development in children with insulin-dependent diabetes. Diabetes Res 1985;2:237-241.

30 Parent AS, Teilmann G, Juul A, Skakkebaek NE, Toppari J, Bourguignon JP: The timing of normal puberty and the age limits of sexual precocity: variations around the world, secular trends, and changes after migration. Endocr Rev 2003;24:668-693.

31 Danielson KK, Palta M, Allen C, D’Alessio DJ: The association of increased total glycosylated hemoglobin levels with delayed age at menarche in young women with type 1 diabetes. J Clin Endocrinol Metab 2005;90: 6466-6471.

32 Picardi A, Cipponeri E, Bizzarri C, Fallucca S, Guglielmi C, Pozzilli P: Menarche in type 1 diabetes is still delayed despite good metabolic control. Fertil Steril doi:10.1016/j. fertnstert.2007.09.0352008.

33 Lombardo F, Zalzano G, Crisafulli G, Valenzise M, Zirilli G, Manzo V, Aversa T, De Luca F: Menarcheal timing in intensively treated girls with type 1 diabetes mellitus. Nutr Metab Cardiovasc Dis. doi:10.1016/j. numecd.2007.12.002 2008, in press.

-34 Elamin A, Hussein O, Tuvemo T: Growth, puberty, and final height in children with Type 1 diabetes. J Diabetes Complications 2006;20:252-256.

- 35 Kjaer K, Hagen C, Sando SH, Eshoj O: Epidemiology of menarche and menstrual disturbances in an unselected group of women with insulin-dependent diabetes mellitus compared to controls. J Clin Endocrinol Metab 1992;75:524-529.

- 36 Yeshaya A, Orvieto R, Dicker D, Karp M, Ben-Rafael Z: Menstrual characteristics of women suffering from insulin-dependent diabetes mellitus. Int J Fertil Menopausal Stud 1995;40:269-273. 
\37 Adcock CJ, Perry LA, Lindsell DR, Taylor AM, Holly JM, Jones J, Dunger DB: Menstrual irregularities are more common in adolescents with type 1 diabetes: association with poor glycaemic control and weight gain. Diabet Med 1994;11:465-470.

38 Dunger DB, Ahmed ML, Ong KK: Early and late weight gain and the timing of puberty. Mol Cell Endocrinol 2006;254-255:140145.

>39 Snell-Bergeon JK, Dabelea D, Ogden LG, Hokanson JE, Kinney GL, Ehrlich J, Rewers M: Reproductive history and hormonal birth control use are associated with coronary calcium progression in women with type 1 diabetes mellitus. J Clin Endocrinol Metab 2008;93:2142-2148.

-40 Schroeder B, Hertweck SP, Sanfilippo JS Foster MB: Correlation between glycemic control and menstruation in diabetic adolescents. J Reprod Med 2000;45:1-5.

41 Eyzaguirre FC, Iñiguez G, P L, Avila A, Torrealba I, Giadrosich V, Pérez-Bravo F, Cassorla F, Codner E: Frequency of ovulatory cycles in young adolescents with type 1 diabetes mellitus. Horm Res 2007;68:9.

42 Sherman LS, Rogers DG, Gabbay KH: Pulsatility of luteinizing hormone during puberty is dependent on recent glycemic control. Adolesc Paediatr Gynecol 1991;4:87-92.

$\checkmark 43$ Codner E, Mook-Kanamori D, Bazaes RA, Unanue N, Sovino H, Ugarte F, Avila A, Iniguez G, Cassorla F: Ovarian function during puberty in girls with type 1 diabetes mellitus: response to leuprolide. J Clin Endocrinol Metab 2005;90:3939-3945.

44 Meyer K, Deutscher J, Anil M, Berthold A, Bartsch M, Kiess W: Serum androgen levels in adolescents with type 1 diabetes: relationship to pubertal stage and metabolic control. J Endocrinol Invest 2000;23:362-368.

-45 Daneman D, Rodin G, Jones J, Colton P, Rydall A, Maharaj S, Olmsted M: Eating disorders in adolescent girls and young adult women with type 1 diabetes. Diabetes Spectr 2002;15:83-105.
46 Martinez-Aguayo A, Araneda JC, Fernandez D, Gleisner A, Perez V, Codner E: Tobacco, alcohol, and illicit drug use in adolescents with diabetes mellitus. Pediatr Diabetes 2007;8:265-271.

47 Escobar-Morreale HF, Roldan B, Barrio R, Alonso M, Sancho J, de la Calle H, GarciaRobles R: High prevalence of the polycystic ovary syndrome and hirsutism in women with type 1 diabetes mellitus. J Clin Endocrinol Metab 2000;85:4182-4187.

48 Roldan B, Escobar-Morreale HF, Barrio R, de la Calle H, Alonso M, Garcia-Robles R, Sancho J: Identification of the source of androgen excess in hyperandrogenic type $1 \mathrm{di}-$ abetic patients. Diabetes Care 2001;24:12971299.

49 Amin R, Schultz C, Ong K, Frystyk J, Dalton RN, Perry L, Orskov H, Dunger DB: Low IGF-I and elevated testosterone during puberty in subjects with type 1 diabetes developing microalbuminuria in comparison to normoalbuminuric control subjects: the $\mathrm{Ox}$ ford Regional Prospective Study. Diabetes Care 2003;26:1456-1461.

50 Haffner SM, Klein R, Dunn JF, Moss SE, Klein BE: Increased testosterone in type I diabetic subjects with severe retinopathy. Ophthalmology 1990;97:1270-1274.

51 Virdis R, Zampolli M, Street ME, Vanelli M, Potau N, Terzi C, Ghizzoni L, Ibanez L: Ovarian 17-alpha-hydroxyprogesterone responses to GnRH analog testing in oligomenorrheic insulin-dependent diabetic adolescents. Eur J Endocrinol 1997;136:624629.

52 Remer T, Maser-Gluth C, Boye KR, Hartmann MF, Heinze E, Wudy SA: Exaggerated adrenarche and altered cortisol metabolism in type 1 diabetic children. Steroids 2006;71: 591-598.
53 Dunger DB, Acerini CL: IGF-I and diabetes in adolescence. Diabetes Metab 1998;24:101107.

54 Bryden KS, Peveler RC, Stein A, Neil A, Mayou RA, Dunger DB: Clinical and psychological course of diabetes from adolescence to young adulthood: a longitudinal cohort study. Diabetes Care 2001;24:1536-1540.

55 Schultz CJ, Konopelska-Bahu T, Dalton RN, Carroll TA, Stratton I, Gale EA, Neil A, Dunger DB: Microalbuminuria prevalence varies with age, sex, and puberty in children with type 1 diabetes followed from diagnosis in a longitudinal study. Oxford Regional Prospective Study Group. Diabetes Care 1999;22:495-502.

>56 Ahmed ML, Ong KK, Watts AP, Morrell DJ, Preece MA, Dunger DB: Elevated leptin levels are associated with excess gains in fat mass in girls, but not boys, with type 1 diabetes: longitudinal study during adolescence. J Clin Endocrinol Metab 2001;86: 1188-1193

57 Iñiguez G, Torrealba IM, Avila A, Cassorla F, Codner E: Adiponectin serum levels and their relationships to androgen concentrations and ovarian volume during puberty in girls with type 1 diabetes mellitus. Horm Res 2008;70:112-117.

58 Salerno M, Argenziano A, Di Maio S, Gasparini N, Formicola S, De Filippo G, Tenore A: Pubertal growth, sexual maturation, and final height in children with IDDM: effects of age at onset and metabolic control. Diabetes Care 1997;20:721-724.

59 Donaghue KC, Fairchild JM, Craig ME, Chan AK, Hing S, Cutler LR, Howard NJ, Silink M: Do all prepubertal years of diabetes duration contribute equally to diabetes complications? Diabetes Care 2003;26:12241229.

60 Schriock EA, Winter RJ, Traisman HS: Diabetes mellitus and its effects on menarche. J Adolesc Health Care 1984;5:101-104. 